\title{
A 24-Year-Old Male with Gigantism, Growth Hormone Deficiency, Suspected Clivus Chordoma, Primary Hypothyroidism, Hypogonadism and Pancytopenia
}

\author{
W.A. Arsana, M.I. Diah Pramudianti \\ Department of Clinical Pathology, Medical Faculty, Sebelas Maret University/Moewardi Hospital, Surakarta, Indonesia. \\ E-mail:a_gunq@yahoo.co.id
}

\begin{abstract}
Pituitary gigantism is a condition caused by excessive secretion of Growth Hormone (GH). The GH is the most common pituitary hormone-deficient in pituitary disease. Chordoma is a bone primary tumor that grows slowly and is rarely found. Hypothyroidism is a pathological condition due to thyroid hormone deficiency. Symptoms of hypogonadism are non-specific including libido disorders, erectile dysfunction, and decreased muscle mass and no hair growth in the head or body. A 24-year-old male came with pain in the knee. Physical examination showed increased growth of natural and body parts as well as the loss of body hair. Laboratory investigations revealed pancytopenia, increased prolactin; decreased $\mathrm{GH}$, Insulin-Like Growth Factor-1 (IGF-1) and testosterone; increased Thyroid-Stimulating Hormone (TSH), decreased Free Triiodothyronine (FT3) and Free Thyroxine (FT4). Ahead MRI demonstrated the presence of a mass in the clivus. In this case, the patient presented with clinical gigantism. However, laboratory examination showed decreased GH and IGF-1 which might be due to the suppressive effect of mass on the clivus bone to the pituitary. Further examinations were needed to clear the suspicion of hypothyroid. Hypogonadism can result from suppression in the pituitary. Pancytopenia can be caused by a deficiency of GH or from hypothyroidism. Gigantism may occur with GH and IGF-1 deficiency due to suppressed pituitary caused by chordoma.
\end{abstract}

Keywords: Gigantism, clivus chordoma, primary hypothyroidism, hypogonadism, pancytopenia

\section{INTRODUCTION}

Pituitary gigantism is a condition caused by the excessive secretion of Growth Hormone (GH). When $\mathrm{GH}$-secreting pituitary tumors appear before the fusion of epiphyses growth plates in children its called gigantism. Conversely, when it appears in adults (after complete epiphyseal fusion), there is no linear growth, but a change in acral its called acromegaly. Growth hormone-secreting tumors are generally sporadic but may appear as a part of syndromes such as Multiple Endocrine Neoplasia (MEN) type 1, Mc Cune Albright syndrome (MAS), and Carney complex. $^{1-4}$

Pituitary gigantism and acromegaly are extremely rare conditions. In Newcastle, there were 2.8 new cases/1 million adult population. A higher incidence was reported from Sweden with 68 cases/million population. The average age for the diagnosis of acromegaly is 40-45 years and the slow onset causes the disease to be diagnosed 10-12 years after the onset. ${ }^{2}$ Gigantism is generally caused by a pituitary adenoma that produces $\mathrm{GH}$, but it may also be caused an ectopic tumor producing Growth-Hormone-Releasing Hormone (GHRH) or hypothalamic dysfunction with hypersecretion of $\mathrm{GHRH}^{1,5}$

Although patients with acromegaly have elevated serum $\mathrm{GH}$ levels, it is difficult to distinguish a normal increase in serum $\mathrm{GH}$, because $\mathrm{GH}$ levels fluctuate day and night. The $\mathrm{GH}$ examination is not very meaningful for diagnosis. Growth hormone serum can be elevated in conditions such as fasting, exercise, stress, and sleep. The concentrations fluctuate from $<0.5$ $\mathrm{ng} / \mathrm{mL}$ during the day to $20 / 30 \mathrm{ng} / \mathrm{mL}$ at night or on severe activity. Growth hormone serum can also be increased in patients with uncontrolled Diabetes Mellitus (DM), liver disease, and malnutrition. ${ }^{3,6}$

Serum IGF-1 is a screening test for acromegaly. Serum IGF-1 does not fluctuate like GH which its affected by food intake, exercise and sleep conditions as in $\mathrm{GH}$ and increased in patients with clinical acromegaly. Under normal conditions, serum IGF-1 increases in puberty and decreases thereafter. Serum IGF-1 is higher in female and it also increases during pregnancy. ${ }^{3}$ 
The laboratory diagnosis of acromegaly or gigantism is confirmed by serum GH examination after glucose loading and $\mathrm{GH}$ dependent circulating molecules such as IGF-1 and IGF-binding protein 3 (IGFBP-3) ${ }^{1-3}$ Laboratory criteria for the diagnosis of acromegaly are $\mathrm{GH} 24$ hours level $>2.5 \mathrm{ng} / \mathrm{mL}$, lowest $\mathrm{GH}$ levels $>1 \mathrm{ng} / \mathrm{mL}$ after glucose administration and/or elevated serum IGF-1. Approximately $10 \%$ of patients with acromegaly have normal GH or IGF-1 levels, or both are normal at diagnosis. Thus it needs re-examination to know the actual levels of $\mathrm{GH}$ and IGF-1. ${ }^{3}$

The GH is the most common pituitary hormonedeficient in pituitary disease and causes negative effects on the body, cardiovascular risk, and quality of life. The incidence of $\mathrm{GH}$ deficiency disease in children is about $1: 4,000$ to $1: 10,000$ births, whereas $3-30 \%$ is a genetic disorder. In some studies, about $25 \%$ of children diagnosed with $\mathrm{GH}$ deficiency have organic disorders, such as trauma, Central Nervous System (CNS) tumors, inflammation, irradiation, or abnormal anatomical conditions of the hypothalamus or pituitary gland. ${ }^{3}$ Idiopathic GH deficiency is the most common etiology of $\mathrm{GH}$ deficiency in children.

Children with GH deficiency, generally appear with short posture and slow growth which do not correspond to their age. Diagnosis of GH deficiency in children is very complex and other causes of short posture must be ruled out. ${ }^{3}$ The onset of $\mathrm{GH}$ deficiency in adults appears as a part of a combination of pituitary hormone deficiency and is generally associated with pituitary adenoma and/or as a result of surgical or radiotherapy. Growth hormone deficiency in adults does not show typical symptoms. In adults, GH deficiency is associated with changes in body composition, metabolic changes, decreased capacity to perform activities, and impaired quality of life. Adults with GH deficiency have decreased skeletal muscle, decreased body mass, increased fat mass. Patients also experience decreased bone mass thus increasing the risk of osteoporosis. $^{7.9}$

In this paper, we will report a case with clinical gigantism but the laboratory examination obtained a low level of serum GH and IGF-1.

\section{CASE}

A 24-year-old male came with pain in the knee since June 2017. He was still able to walk. He felt his calves tight as he walked too long. He went for treatment to primary health care and was X-rayed. The results of the left knee radiology examination on June 13, 2017, was impressed bones articulation arthritis on the left knee. The patient was referred to the hospital due to shortness of breath and fatigue. In the hospital, he was treated by cardiologists, neurologists, and orthopedists. The patient routinely controlled every two weeks to one month and was given medication of calcium and vitamins. The patient was then referred to our hospital in early September 2017. History revealed no body hair growth and Adam's apple, and small genitals since he was 14 years old. His height was normal, but it changed drastically after he graduated from high school. He also complained of headaches and blurred vision. None of his family experienced similar symptoms. The patient was the last child of four siblings (Figure 1).

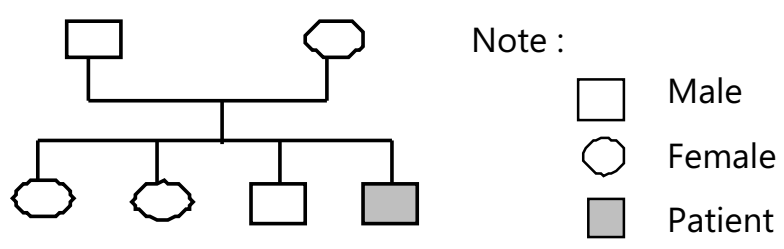

Figure 1. Family tree

Physical examination revealed a moderate general condition, blood pressure of $90 / 60 \mathrm{mmHg}$, respiratory rate $20 /$ minute, heart rate $84 /$ minute, temperature of $36.5^{\circ} \mathrm{C}$, weight of $75 \mathrm{~kg}$ and height of $183 \mathrm{~cm}$, tall stature, macrocephaly, head diameter $55.5 \mathrm{~cm}$, glabella distance $2.5 \mathrm{~cm}$, corneal distance $6 \mathrm{~cm}$, right ear and left ear $17 \mathrm{~cm}$ long and chest circumference $97 \mathrm{~cm}$. There was a lump in the back with the size of $12 \times 12 \times 2.5 \mathrm{~cm}$ with no tenderness and no hyperemia, ill-defined, and attached to the base. The diameter of the finger and toe bones were elongated (Figure 2). The penis length was $3 \mathrm{~cm}$, with a diameter of testis $1.3 \mathrm{~cm}$. Routine laboratory investigation on November 3, 2017, showed pancytopenia (Table 1).

Radiology imaging of thoracolumbar, right shoulder, and coxae on November 3, 2017, revealed no abnormalities (Figure 3). Peripheral blood smear on January 18, 2018, obtained suspected pancytopenia with the recommendation for Bone Marrow Puncture (BMP) (Figure 4). Contrast CT Scan examination on January 15, 2018, concluded no visible lesions in the brain parenchyma, no visible mass picture in intrasellar and suprasellar, and hypotrophy concha nasalis inferior right-left, and recommendation for contrast head MRI (Figure 5). Advanced laboratory investigation revealed increased prolactin; decreased GH, IGF-1 and testosterone; increased TSH, decreased FT3 and FT4 (Table 2). 

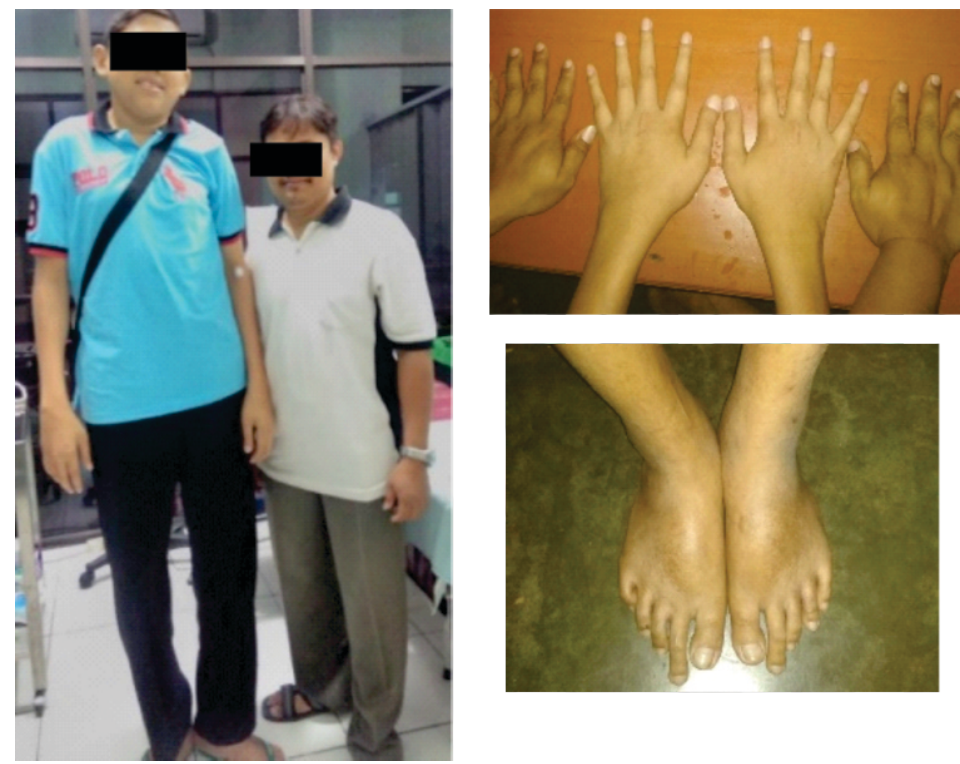

Figure 2. Clinical features of gigantism in our patient

Table 1. Laboratory values of the patient November 3, 2017

\begin{tabular}{lccc}
\hline \multicolumn{1}{c}{ Test } & $\mathbf{0 3 / 1 1 / 2 0 1 7}$ & Unit & Normal Range \\
\hline Hematology & & & \\
Hemoglobin (Hb) & 9.9 & $\mathrm{~g} / \mathrm{dL}$ & $13.5-17.5$ \\
Hematocrit (HCT) & 31 & $\%$ & $33-45$ \\
White Blood Cells (WBC) & 3.0 & $10^{3} / \mathrm{uL}$ & $4.5-11.0$ \\
Platelet (PLT) & 110 & $10^{3} / \mathrm{uL}$ & $150-450$ \\
Red Blood Cells (RBC) & 3.85 & $10^{6} / \mathrm{uL}$ & $4.50-5.90$ \\
Mean Cell Volume (MCV) & 80.3 & $/ \mathrm{um}$ & $80.0-96.0$ \\
Mean Corpuscular Hemoglobin (MCH) & $\mathbf{2 5 . 7}$ & $\mathrm{pg}$ & $28.0-33.0$ \\
Mean Corpuscular Hemoglobin Concentration (MCHC) & 32.0 & $\mathrm{~g} / \mathrm{dL}$ & $33.0-36.0$ \\
Red Cell Distribution Width (RDW) & 14.0 & $\%$ & $11.6-14.6$ \\
Mean Platelet Volume (MPV) & 12.7 & $\mathrm{fl}$ & $7.2-11.1$ \\
Platelet Distribution Width (PDW) & 16 & $\%$ & $25-65$ \\
Eosinophils & 4.30 & $\%$ & $0.00-4.00$ \\
Basophils & 0.30 & $\%$ & $0.00-2.00$ \\
Neutrophils & 39.00 & $\%$ & $55.00-80.00$ \\
Lymphocytes & 47.20 & $\%$ & $22.00-44.00$ \\
Monocytes & 9.20 & $\%$ & $0.00-7.00$ \\
Reticulocyte & 1.72 & $\%$ & $0.50-1.50$ \\
Reticulocyte Hemoglobin Content (CHr) & 28.7 & $\mathrm{pg}$ & $28.0-35.0$ \\
Clinical chemistry & & & \\
Glucose & 99 & $\mathrm{mg} / \mathrm{dL}$ & $60-140$ \\
Aspartate Aminotransferase (AST) & 35 & $\mathrm{u} / \mathrm{l}$ & $<35$ \\
Alanine Aminotransferase (ALT) & 13 & $\mathrm{u} / \mathrm{l}$ & $<45$ \\
Creatinine & $\mathrm{mg} / \mathrm{dL}$ & $0.9-1.3$ \\
Ureum & $\mathrm{mg} / \mathrm{dL}$ & $<50$ \\
Electrolytes & 17 & & \\
Sodium & & $\mathrm{mmol} / \mathrm{L}$ & $136-145$ \\
Potassium & $\mathbf{0 . 7}$ & $\mathrm{mmol} / \mathrm{L}$ & $3.3-5.1$ \\
Calcium Ion & $\mathbf{1 3 5}$ & $\mathrm{mmol} / \mathrm{L}$ & $1.17-1.29$ \\
\hline
\end{tabular}


Radiology imaging of thoracolumbar, right shoulder, and coxae on November 3, 2017, revealed no abnormalities (Figure 3). Peripheral blood smear on January 18, 2018, obtained suspected pancytopenia with the recommendation for Bone Marrow Puncture (BMP) (Figure 4). Contrast CT Scan examination on January 15,2018 , concluded no visible lesions in the brain parenchyma, no visible mass picture in intrasellar and suprasellar, and hypotrophy concha nasalis inferior right-left, and recommendation for contrast head MRI (Figure 5). Advanced laboratory investigation revealed increased prolactin; decreased GH, IGF-1 and testosterone; increased TSH, decreased FT3 and FT4 (Table 2).

Head MRI examination on January 31, 2018, revealed a clivus mass eroding the clivus bone extending to intracellular with emphasis on the hypophysis to the superior, suspected clivus chordoma (Figure 6).
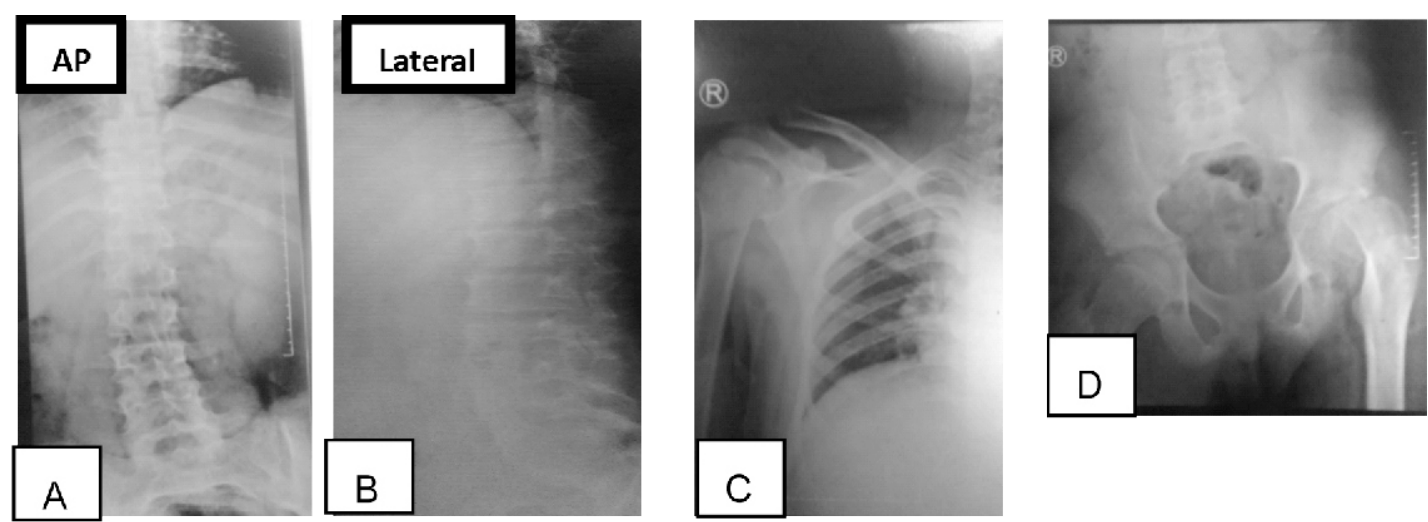

Figure 3. Radiology Imaging (A) (B) Anteroposterior Thoracolumbar (AP) / Lateral (C) Right Shoulder (D) Coxae AP
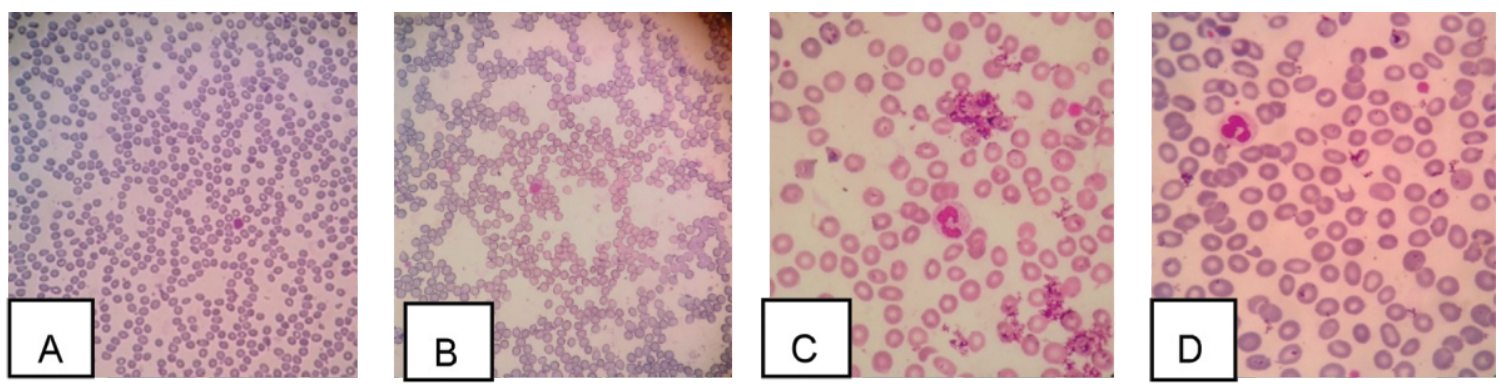

Figure 4. (A) (B) 10x40 magnification with Wright-Giemsa staining(C) (D) $10 \times 100$ magnification with Wright-Giemsa staining

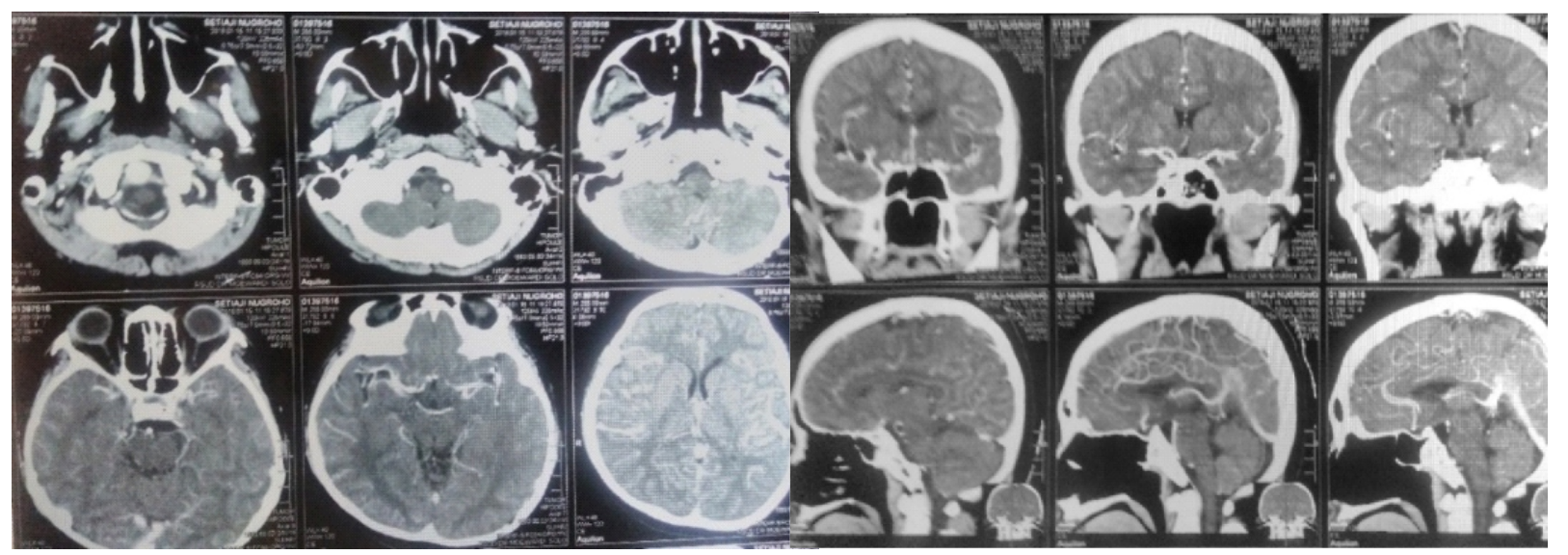

Figure 5. Head CT Scan 
Table 2. Advanced laboratory examination results

\begin{tabular}{|c|c|c|c|c|c|c|c|c|}
\hline Test & $\begin{array}{c}14 / 11 / 20 \\
17 \\
\text { (Prodia) }\end{array}$ & $\begin{array}{c}11 / 12 / 20 \\
17 \\
\text { (Prodia) }\end{array}$ & $02 / 01 / 2018$ & $\begin{array}{c}18 / 01 / 20 \\
18\end{array}$ & $\begin{array}{c}02 / 02 / 20 \\
18\end{array}$ & $\begin{array}{c}02 / 02 / 20 \\
18\end{array}$ & Unit & Normal Range \\
\hline \multicolumn{9}{|l|}{ Hematology } \\
\hline $\mathrm{Hb}$ & & & & 10.3 & & & $\mathrm{~g} / \mathrm{dL}$ & $13.5-17.5$ \\
\hline Hct & & & & 32 & & & $\%$ & $33-45$ \\
\hline WBC & & & & 2.9 & & & $10^{3} / \mathrm{uL}$ & $4.5-11.0$ \\
\hline PLT & & & & 83 & & & $10^{3} / \mathrm{uL}$ & $150-450$ \\
\hline $\mathrm{RBC}$ & & & & 4.13 & & & $10^{6} / \mathrm{uL}$ & $4.50-5.90$ \\
\hline MCV & & & & 77.5 & & & /um & $80.0-96.0$ \\
\hline $\mathrm{MCH}$ & & & & 25.0 & & & $\mathrm{pg}$ & $28.0-33.0$ \\
\hline $\mathrm{MCHC}$ & & & & 32.3 & & & $\mathrm{~g} / \mathrm{dL}$ & $33.0-36.0$ \\
\hline RDW & & & & 13.6 & & & $\%$ & $11.6-14.6$ \\
\hline MPV & & & & 12.0 & & & $\mathrm{fl}$ & $7.2-11.1$ \\
\hline PDW & & & & 24 & & & $\%$ & $25-65$ \\
\hline Eosinophils & & & & 3.26 & & & $\%$ & $0.00-4.00$ \\
\hline Basiphils & & & & 0.48 & & & $\%$ & $0.00-2.00$ \\
\hline Neutrophils & & & & 38.29 & & & $\%$ & $55.0-80.0$ \\
\hline Lymphocyte & & & & 51.63 & & & $\%$ & $22.0-44.0$ \\
\hline Monocyte & & & & 6.34 & & & $\%$ & $0.00-7.00$ \\
\hline \multicolumn{9}{|l|}{$\begin{array}{l}\text { Clinical } \\
\text { chemistry }\end{array}$} \\
\hline Creatinine & & & 0.7 & 0.7 & & & $\mathrm{mg} / \mathrm{dL}$ & $0.9-1.3$ \\
\hline Ureum & & & 15 & 13 & & & $\mathrm{mg} / \mathrm{dL}$ & $<50$ \\
\hline \multicolumn{9}{|l|}{ Electrolyte } \\
\hline Sodium & & & & 138 & & & $\mathrm{mmol} / \mathrm{L}$ & $136-145$ \\
\hline Potasium & & & & 3.6 & & & $\mathrm{mmol} / \mathrm{L}$ & $3.3-5.1$ \\
\hline Calcium Ion & & & & 1.15 & & & $\mathrm{mmol} / \mathrm{L}$ & $1.17-1.29$ \\
\hline \multicolumn{9}{|l|}{ Serology } \\
\hline $\mathrm{HBsAg}$ & & & Non reactive & & & & & $N R$ \\
\hline \multicolumn{9}{|l|}{ Endocrinology } \\
\hline Prolactin & 18.5 & & & & & & $\mathrm{ng} / \mathrm{mL}$ & $2.1-17.7$ \\
\hline IGF-1 & $<15$ & & & & & & $\mathrm{ng} / \mathrm{mL}$ & $107-367$ \\
\hline $\mathrm{GH}$ & & $<0.05$ & & & & & $\mathrm{ng} / \mathrm{mL}$ & ? 3 \\
\hline TSH & & & & & 12.35 & & $\mathrm{uI} / \mathrm{mL}$ & $0.40-4.20$ \\
\hline Free T3 & & & & & 2.78 & & $\mathrm{pmol} / \mathrm{l}$ & $3.00-8.00$ \\
\hline Free T4 & & & & & 5.79 & & $\mathrm{pmol} / \mathrm{l}$ & $10.3-34.7$ \\
\hline Testosterone & & & & & & $<2.5$ & $\mathrm{ng} / \mathrm{dL}$ & $249-836$ \\
\hline
\end{tabular}

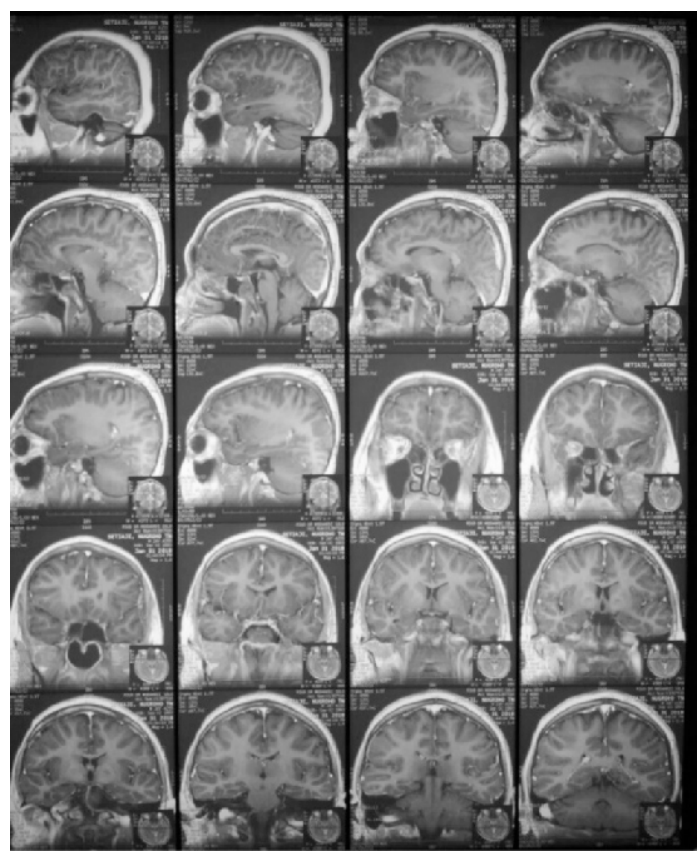

Figure 6. Head MRI 


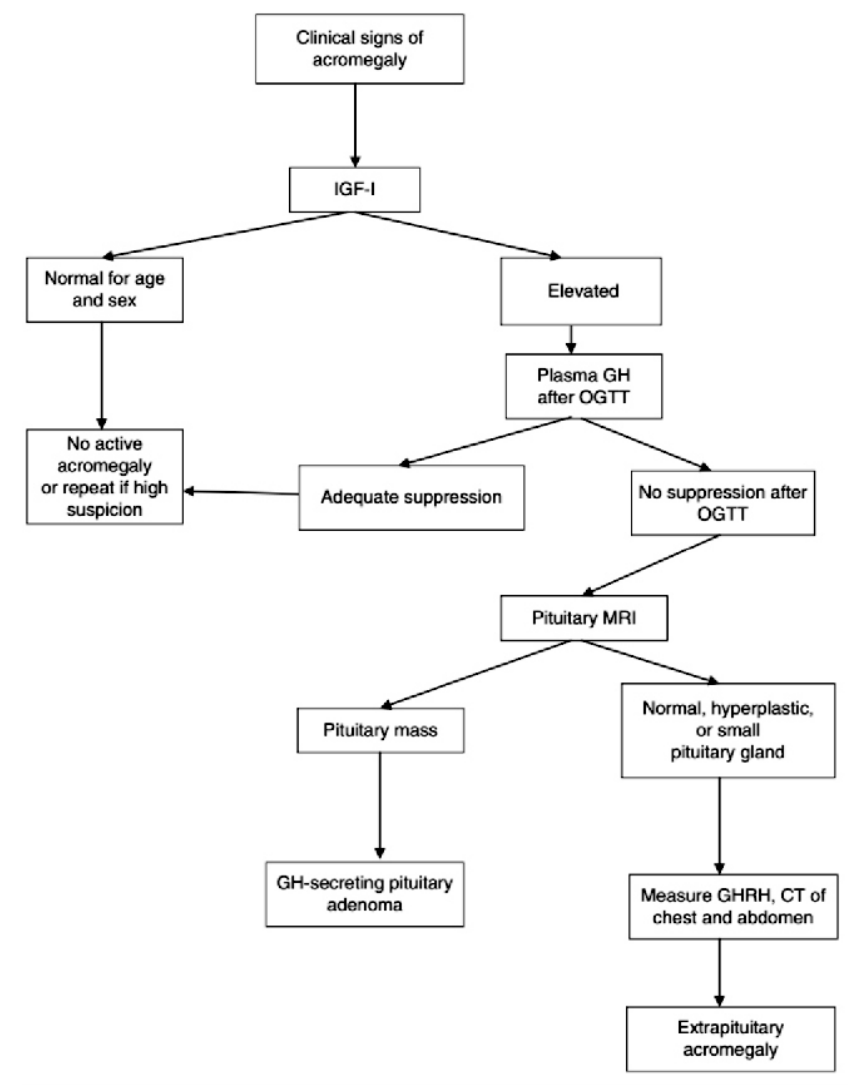

Figure 7. Diagnostic algorithm for acromegaly ${ }^{10}$

\section{DISCUSSION}

In this case, the patient clinical findings corresponded to gigantism. However, laboratory examination revealed a decreased level of $\mathrm{GH}$ and IGF-1. MRI examination showed that the mass on the clivus bone suppressed the anterior pituitary. Gigantism, in this case, may be caused by the small mass on the clivus bone, resulting in $\mathrm{GH}$ hypersecretion of the anterior pituitary. However, the enlargement of mass in the clivus causes an emphasis on the pituitary resulting a decrease in $\mathrm{GH}$.

Prognosis of patients with gigantism depended on the control of $\mathrm{GH}$ hypersecretion. The survival rate improved with additional surgery and therapeutic measures. In our case, a low GH result was obtained but no short stature was attributed to GH deficiency. Growth hormone deficiency may be due to the suppressive effect of mass on the clivus bone. Laboratory diagnosis of gigantism was confirmed from the examination of $\mathrm{GH}$ after administration of glucose load and examination of IGF- $1 .{ }^{10}$ Diagnostic algorithm for acromegaly can be seen in Figure 7 .

Chordomas can be detected by radiological imaging. MRI scan is recommended for help diagnosing chordoma and FNAB examination is important to establish the diagnosis before performing the resection. ${ }^{11,12}$ The current therapeutic option for chordoma is transsphenoidal (gross total resection) surgery followed by radiotherapy. ${ }^{13,14}$ The postoperative and radiotherapy recurrence rates are about $50-60 \%$ in 5 years and $40-50 \%$ in 10 years. ${ }^{15,16}$ The clivus is a structural part of the skull base and separates it from other structures around the face and neck. ${ }^{17}$ The location of the clivus bone can be seen in Figure 8.

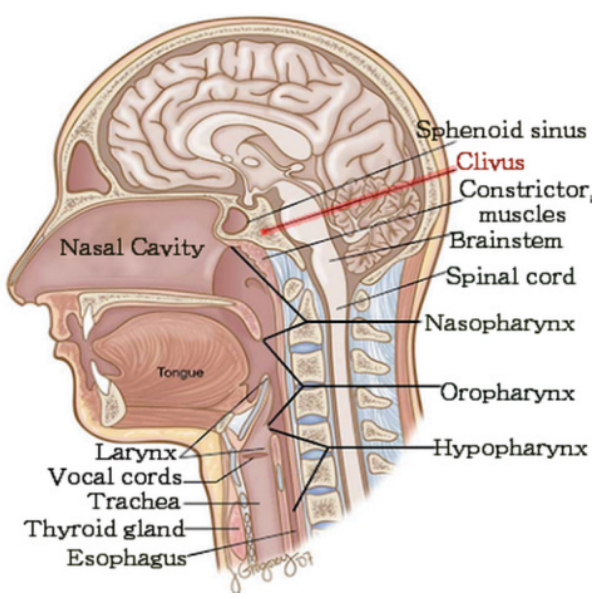

Figure 8. Clivus bone ${ }^{17}$ 


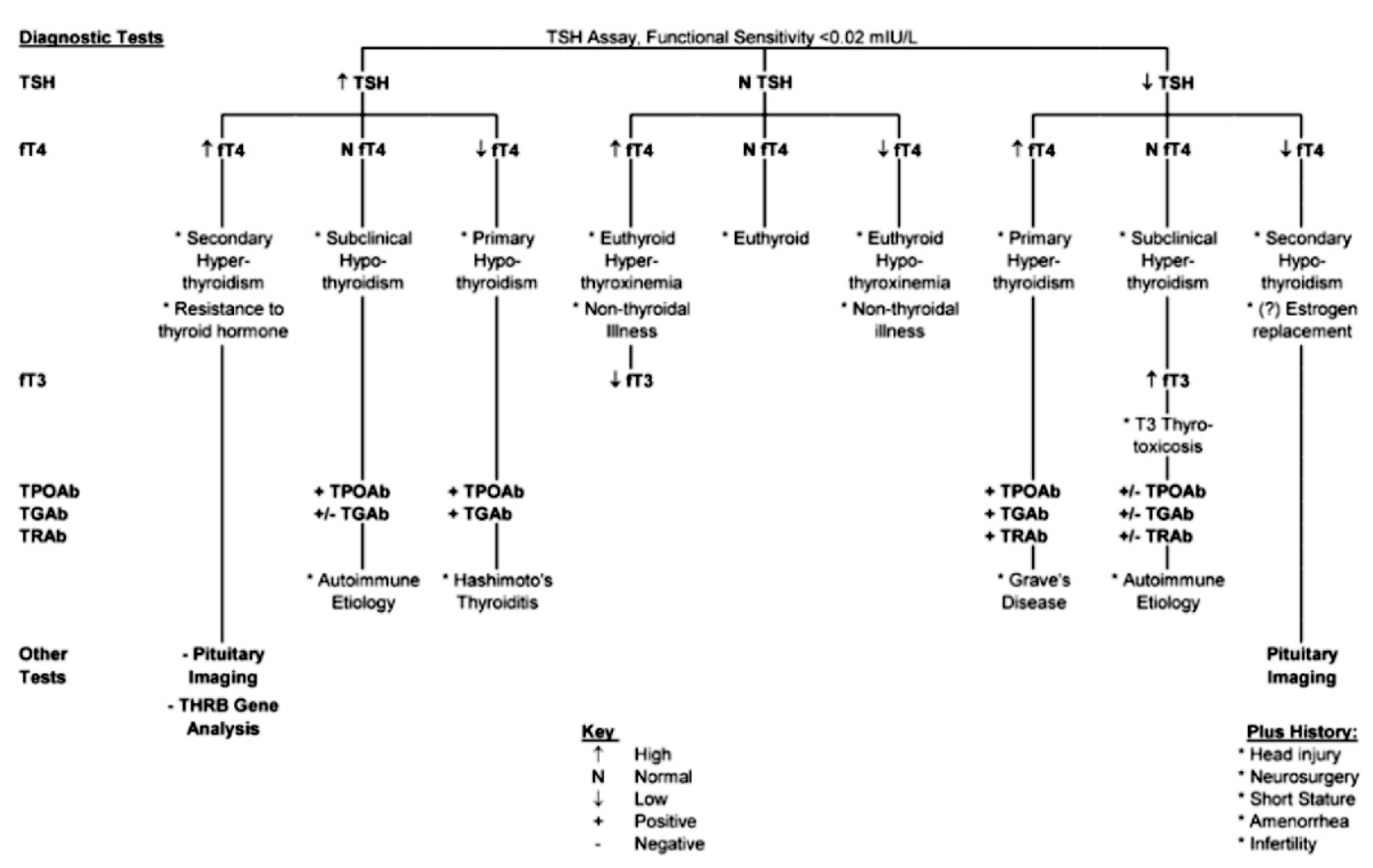

Figure 9. Thyroid function diagnostic algorithm ${ }^{20}$

In our case, a mass on the clivus bone was suspected as a clivus chordoma causing suppression of the anterior pituitary leading to hypopituitarism. The mass on this clivus bone was detected by contrast MRI imaging.

Hypothyroidism is a pathological condition that arises from thyroid hormone deficiency. Hypothyroidism is divided into primary (thyroid hormone deficiency), secondary (TSH deficiency), tertiary [Thyrotropin Releasing Hormone (TRH) and peripheral (extrathyroid) deficiency. ${ }^{18,19}$

In our case hypothyroidism with high serum TSH and low free T3 and free T4 test results were leading to primary hypothyroidism. ${ }^{20}$ Thus it could not be explained whether the hypothyroidism stood-alone or was caused by tumors on the clivus bone that suppressed the pituitary. To help the diagnosis of thyroid disorders it was advisable to screen for TPOAb and TGAb (Figure 9).

Hypogonadism in males is a clinical symptom due to failure to produce normal testosterone or sperm or both. It may occur due to the disease in the testis (primary hypogonadism) or dysfunction of the hypothalamus unit of the pituitary (secondary hypogonadism). ${ }^{21}$ Secondary hypogonadism may occur due to the effects of a mass that suppress the anterior pituitary. Symptoms of hypogonadism may be nonspecific including libido disorders, erectile dysfunction, and decreased muscle mass and no body hair growth. ${ }^{22,23}$
In our case, hypogonadism may be caused by a mass on the clivus bone suppressing the pituitary. Further examination may be recommended for Luteinizing Hormone (LH) and Follicle-Stimulating Hormone (FSH) examinations to differentiate primary and secondary hypogonadism.

Pancytopenia is a state of diminished all blood cell lines characterized by anemia, leukopenia, and thrombocytopenia. Pancytopenia caused by pituitary hormone deficiency is very rare. The relation of pancytopenia to pituitary hormones is still not clearly understood. Pituitary hormone deficiency can affect hematopoiesis. Severe hypothyroidism can also cause normocytic anemia. Growth hormone deficiency, cortisol, and prolactin may cause bone marrow abnormalities. ${ }^{24,25}$

In this case, pancytopenia may be caused by a GH deficiency or may be from its hypothyroidism. Bone marrow puncture is recommended to determine whether the pancytopenia was derived from primary bone marrow or as an effect of pituitary hormone deficiency.

As far as we know, this case is the first case of gigantism with the low level of GH and IGF-1.

\section{CONCLUSION}

Gigantism may occur with deficiency GH and IGF-1 due to suppressed pituitary caused by chordoma. 


\section{REFERENCES}

1. Young WF. The netter collection of medical illustrations: The endocrine system. $2^{\text {nd }}$ Ed., Philadelphia, Elsevier, 2011; 21-22.

2. Holt IG, Hanley NA. Essential endocrinology and diabetes. $6^{\text {th }}$ Ed., West Sussex: Blackwell Publishing, p 65-98; 2012.

3. Melmed S. Endocrinology: Adult and pediatric. $7^{\text {th }}$ Ed., Philadelphia, Elsevier, 2016; 209-226e7.

4. Hannah-Shmoni F, Trivellin G, Stratakis CA. Genetics of gigantism and acromegaly. Growth Horm IGF Res, 2016; 30-31: 37-41.

5. Rhee N, Jeong K, Yang EM, Kim CJ. Gigantism caused by growth hormone-secreting pituitary adenoma. Ann Pediatr Endocrinol Metab, 2014; 19(2): 96-99.

6. Durmaz SA, Bahceci M, Tuzku A, Gokalp D, Guzel A, Ayag $\mathrm{H}$. An acromegalic patient with low Insulin-Like Growth Factor-1 levels: it may not be found to be elevated during diagnosis of acromegaly each time. Turk1 sh Journal of Clinics and Laboratory, 2015; 6: 45-48.

7. Ayuk J, Sheppard MC. Growth hormone and its disorders. Postgrad Med J, 2006; 82(963): 24-30.

8. Stagi S, Scalini P, Farello G, Verrotti A. Possible effects of an early diagnosis and treatment in patients with growth hormone deficiency: The state of art. Italian Journal of Pediatrics, 2017; 43(1): 81.

9. Devesa J, Almenglo C, Devesa P. Multiple effects of growth hormone in the body: Is it really the hormone for growth?. Clinical Medicine Insights: Endocrinology and Diabetes, 2016; 9: 47-7.

10. Cordido F, Arnes JAG, Aspiroz MM, Vela ET. Practical guidelines for diagnosis and treatment of acromegaly. Endocrinol Nutr, 2013; 60(8):457.e1-457.e15.

11. Labidi M, Watanabe K, Bouazza S, Bresson D, Bernat AL, George B, Froelich S. Clivus chordomas: A systematic review and meta-analysis of contemporary surgical management. J Neurosurg Sci, 2016; 60(4): 476-84.

12. Walcott BP, Nahed BV, Mohyeldin A, Coumans JV, Kahle KT, Ferreira MJ. Chordoma: Current concepts, management, and future directions. Lancet Oncol, 2012; 13(2): e69-76.
13. Hirosawa RM, Santos $A B A$, Franca MM, Vebris VE, Castro AVB, Zanini MA, Nunes VS. Intrasellar chondroid chordoma: A case report. ISRN Endocrinology, 2011; 1-5.

14. Falconer MA, Bailey IC, Duchen LW. Surgical treatment of chordoma and chondroma of the skull base. J Neurosurg, 1968; 29(3): 261-75.

15. Fernandez-Miranda J C, Gardner PA, Snyderman $\mathrm{CH}_{\text {, }}$ Devaney KO, Mendenhall WM, Suarez C, Rinaldo A, Ferlito A. Clival chordomas: A pathological, surgical, and radiotherapeutic review. Wiley Online Library, 2013; 892-906.

16. Virdi G, McGraw I, MacDuff E, Periasamy K, Sharma H. An atypical presentation of chordoma: Case report and review. Orthop Muscular Syst, 2017; 6:4.

17. What, where is the clivus [cited 2016 Sept 10\}. Available on http://clivustumor.blogspot. co.id/2013/03/what-where-is-clivus.html

18. Chaker L, Bianco AC, Jonklaas J, Peeters RP. Hypothyroidism. Lancet, 2017; 390: 1550-62.

19. Persani L, Brabant G, Dattani M, Bonomi M, FeldtRasmussen U, Fliers E, Gruters A, et al. 2018 European Thyroid Association (ETA) guidelines on the diagnosis and management of central hypothyroidism. Eur Thyroid J, 2018; 1-13

20. Aw TC, Yap CY. Thyroid function tests: Proceedings of Singapore Healthcare. 2011; 20(2): 132-137.

21. Basaria S. Male hypogonadism. Lancet, 2014; 383: 1250-63.

22. Rosenquist KJ, Kaiser UB. Pituitary disorders: Diagnosis and management. $1^{\text {st }}$ Ed., West Sussex, Wiley Blackwell, 2013; 12: 120-129.

23. Dohle GR, Arver S, Bettocchi C, Jones TH, Kliesch S. EAU guidelines on male hypogonadism. European Association of Urology, 2017; 4-8

24. Lang D, Mead JS, Sykes DB. Hormones and the bone marrow: Panhypopituitarism and pancytopenia in a man with a pituitary adenoma. J Gen Intern Med. 2015; 30(5): 692-6.

25. Koh JH, Lee YJ, Kang JH, Choi BK, Jeon YK, Kim SS, Kim $\mathrm{BH}$, Kim IJ. Pancytopenia associated with hypopituitarism in an acromegaly patient: A case report and a review of the literature. Endocrinol Metab. 2012; 27(4): 308-313. 